\title{
Refugees, Persons of Concern, and People on the Move: The Broadening Boundaries of UNHCR
}

\author{
JEFF CRISP
}

\section{Abstract}

This article examines the way in which UNHCR has expanded its range of policy interests and operational activities since its establishment in 1951, focusing on the extension of the organization's mission from refugees to groups such as asylum seekers, returnees, stateless populations, internally displaced persons, and victims of natural disasters. The article identifies the different factors that have contributed to this expansionist process, examines its implications for UNHCR's core mandate, and asks whether the process is an irreversible one.

\section{Résumé}

L'auteur examine la façon dont le Haut Commissariat pour les réfugiés a élargi son éventail d'intérêts en matière de politiques et d'activités opérationnelles depuis sa création en 1951, mettant l'accent sur l'extension du mandat de l'organisation pour inclure des groupes tels les demandeurs d'asile, les rapatriés, les populations apatrides, les déplacés internes et les victimes de catastrophes naturelles. L'auteur identifie les différents facteurs qui ont contribué à cette expansion, examine ses implications pour le mandat principal du HCR et tente de déterminer s'il s'agit d'un processus irréversible.

\section{Introduction}

Since its establishment in 1951, the United Nations High Commissioner for Refugees (UNHCR) has continually broadened the boundaries of its operational activities and policy concerns. This article examines the process of UNHCR expansion, seeks to explain why it has occurred, and raises some questions with respect to its implications.

\section{A Radical Proposal}

In 2003, Dr. Susan Martin, director of the Institute for the Study of International Migration at Georgetown University, presented a paper to a forced migration conference in Chiang Mai, Thailand. In that paper, and in a subsequent book, Dr. Martin made a proposal for a radical reform of the UN's refugee protection and humanitarian architecture, namely,

the replacement of UNHCR with a UN High Commissioner for Forced Migrants, responsible for assistance to and the protection of all forced migrants, including not only refugees ... but also those migrants internally and externally displaced due to repression, conflict, natural disasters and environmental degradation." ${ }^{1}$

Responding in person to Dr. Martin's presentation, I rejected both the feasibility and desirability of her proposal. First, I pointed out, UNHCR did not have the organizational capacity to assume this extended role. While the organization had expanded very rapidly during the 1990s, it had nevertheless been seriously stretched by a spate of major emergencies and repatriation movements in developing countries, as well as the arrival of large numbers of asylum seekers in Europe and other industrialized regions.

Second, I suggested that UNHCR's key donors (the US, Japan, the states of Western Europe, and Canada) had little or no appetite for a further expansion of the organization's budget or range of responsibilities. Spurred on by a number of academic critiques, which argued that UNHCR had become too involved in large-scale relief operations and had lost sight of its core mandate for refugee protection and solutions, those governments, I said, would be very reluctant to support Dr. Martin's bold proposal.

Resting my case against that proposal, I advanced a third argument, based on the supposition that other UN agencies would oppose any initiative to expand UNHCR's mandate from "refugees" to "forced migrants." Indeed, a 1997 bid by 
UNHCR to assume a general responsibility for the coordination of the UN's humanitarian activities had been jointly killed off by UNICEF and the World Food Programme, both of whom reacted very negatively to the idea of being coordinated by an agency which they considered to be a peer, rather than a superior.

\section{Recent developments}

In the six years that have passed since the Chiang Mai conference, I have been proved comprehensively wrong with respect to Dr. Martin's proposal. For in that relatively short space of time, UNHCR has indeed been transformed from the Office of the High Commissioner for Refugees into something which is beginning to resemble an Office of the High Commissioner for Forced Migrants.

And that transformation has been clearly reflected in the language employed by the organization to describe its beneficiaries. For most of its history, UNHCR had been happy to restrict itself to the words "refugees" and "asylum seekers." From the mid-1990s to the mid-2000s, however, the refugee concept was progressively replaced by the broader and vaguer notion of "persons of concern to UNHCR." Most recently, the organization has gone even further, referring to its constituency as "people on the move." 2

But who exactly are these "people on the move" if they are not refugees or asylum seekers? To answer that question, let us look at the different groups of people who have been (or who are in the process of being) drawn into the ambit of UNHCR's policy concerns and operational activities.

\section{Stateless People}

In 1975, UNHCR was given a formal mandate in relation to stateless people, but for the next fifteen years, the organization devoted very little time, effort, or resources to this responsibility. Thus in 1988, an independent commission reported that "UNHCR has remained somewhat indifferent when it comes to the plight of the stateless." 3 That situation has changed radically in recent years, however, and the pursuit of protection and solutions for people without a nationality has become an increasingly central and well-resourced component of UNHCR's work.

\section{Internally Displaced Populations}

UNHCR has worked with internally displaced populations for many years, but its engagement with this group of people from the 1970s to the 1990s was an ad hoc affair. A 2005 UNHCR evaluation, for example, described the organization's approach to internal displacement as "uncertain, inconsistent and unpredictable." In less than a year, however, such uncertainty was brought to an effective end when, in the context of the UN's humanitarian reform process and the introduction of the "Cluster Approach," UNHCR agreed to assume a leading role in relation to IDP protection, emergency shelter, camp co-ordination, and management. Of the 42 million people supported by the organization, 26 million are now IDPs.

Irregular, Stranded, and Survival Migrants

UNHCR's role in relation to asylum seekers expanded significantly in the 1990s, when growing numbers of people sought refugee status in the industrialized states. More recently, as states struggled to respond to the phenomenon of "mixed migrations" in areas such as the Mediterranean, Aegean, Caribbean, the Gulf of Aden, and West Africa, the organization has become increasingly involved in the issues of irregular migration (people moving without the requisite documents and authorization), stranded migrants (people who are stuck in transit countries and who are vulnerable to human rights violations), and survival migrants (people who may not have a claim to refugee status but who are moving in response to situations of serious economic, social, and political stress).

\section{Populations Affected by Climate Change}

In the past two years, UNHCR has expressed a strong interest in the issue of climate change and human mobility. According to a 2008 policy statement, "Climate change is a humanitarian problem. As such, it is of direct interest to humanitarian agencies, including UNHCR." The statement goes on to say, "Some movements prompted by climate change could indeed fall within the traditional refugee law framework, bringing them within the ambit of international or regional refugee instruments, or complementary forms of protection, as well as within UNHCR's mandate."

\section{Natural Disaster Victims}

In recent times, UNHCR has been involved in a number of humanitarian operations related to victims of natural disasters: the Asian tsunami, the Pakistan earthquake, and the Philippines floods, to give just three examples. Recognizing the vulnerability of the people affected by such disasters, as well as the inadequacy of the Cluster Approach in relation to these catastrophes, UNHCR has now signalled its willingness to assume a more prominent (and in some circumstances a leading) international role in the protection of natural disaster victims.

Urban displacement

UNHCR's operational activities since the 1970s have been largely concentrated in rural areas of developing countries, especially in refugee camps. Refugees who moved to urban areas were generally considered to be the exception rather

(C) Jeff Crisp, 2009. This open-access work is licensed under a Creative Commons Attribution-NonCommercial 4.0 International License, which permits use, reproduction and distribution in any medium for non-commercial purposes, provided the original author(s) are credited and the original publication in Refuge: Canada's Journal on Refugees is cited. 
than the norm, and were assumed to present the organization with a range of unwanted financial, operational, and security problems. Their presence in cities and towns was therefore not to be encouraged.

That approach has now been reversed. In late 2009, UNHCR introduced a new urban refugee policy which seeks to legitimize the role of cities as "places of protection," and which commits the organization to a much more creative and constructive engagement with urban refugees. The December 2009 meeting of the High Commissioner's Dialogue focuses more broadly on the issue of "urban displacement," including refugees, IDPs, and returnees.

\section{Palestinians}

UNHCR has never engaged directly with the majority of Palestinian refugees, by virtue of the fact that they are supported by another UN agency, UNRWA (the United Nations Relief and Works Agency for Palestine Refugees in the Near East), which runs extensive programs for them in Jordan, Lebanon, Syria, Gaza, and the West Bank. While this remains UNHCR's firm position, the organization has become aware of the fact that a significant number of Palestinians find themselves out of UNRWA's reach (those in and displaced from Iraq, for example, and those who seek asylum in Europe) and are in some instances confronted with serious protection and solutions problems. Hence a recent UNHCR decision to clarify the status of such Palestinians in relation to the 1951 Refugee Convention. ${ }^{5}$

\section{Explaining the Expansion}

As the previous section of this article has sought to demonstrate, UNHCR has in recent times expanded its operational activities and policy concerns into a number of new areas. But why exactly has this process taken place? There would appear to be four principal reasons.

First, UNHCR has an expansionist history and has consequently developed an expansionist culture. Starting off in 1951 with just a handful of staff members, a minimal budget, and a remit that was restricted to Europe, the organization progressively extended the scope of its work: to Africa in the 1960s; to South Asia, Southeast Asia, and Latin America in the 1970s; to Central America and Southwest Asia in the 1980s; to the Balkans and the former Soviet Union in the 1990s; and to the Middle East since 2000. UNHCR now has more than 6,600 staff members in 118 countries around the world, with a 2009 budget of some $\$ 2.3$ billion. In this respect, the recent extension of the organization's operational activities and policy concerns can be regarded as a counterpart to UNHCR's long-standing experience of geographical expansion.
Second, and more significantly, UNHCR's linguistic shift from "refugees," to "persons of concern," and then to "people on the move" can be attributed to a number of global megatrends, all of which have had important consequences for human security, human rights, human displacement, and human mobility. These include the restructuring of the international political economy following the end of the Cold War, the fallout from the 9/11 attacks and the subsequent launching of the "War on Terror," the accelerated pace of globalization, and changes in the natural environment.

Referring to such trends and to their dynamic and disruptive character, in 2007 UN High Commissioner Antonio Guterres observed that "the $21^{\text {st }}$ century will be defined by the mass movement of people from one community, country and continent to another." "The world, he stated, "is witnessing new and more complex patterns of displacement and migration," prompted by a combination of "climate change, environmental degradation, natural disasters and armed conflicts, some of them initiated and fuelled by a growing competition for scarce resources such as water and grazing land."6

Almost a year later, the High Commissioner elaborated on these themes in an article in the journal Foreign Affairs. "At few times in history," he said, "have so many people been on the move. The extent of human mobility today is blurring the traditional distinctions between refugees, internally displaced people, and international immigrants. Yet attempts by the international community to devise policies to preempt, govern or direct these movements in a rational manner have been erratic." Concluding that "a fast-growing and increasingly mobile human population needs a new humanitarianprotection compact," the High Commissioner evidently envisages a substantive role for UNHCR in the establishment of such arrangements. ${ }^{7}$

Third, the expansion of UNHCR's role can be attributed to the growing international awareness of humanitarian disasters and humanitarian needs, a trend which is reflective of increasingly effective advocacy efforts as well as the growing influence of the media.

The IDP issue provides a good example of this trend. In the late 1980s, a small number of activists, led by Roberta Cohen and Francis Deng, set out to put the neglected issue of internal displacement on the global humanitarian agenda. By means of their assiduous advocacy efforts, this objective was steadily attained, supported by the substantial publicity given to a succession of IDP crises in countries such as Angola, Colombia, Liberia, Sierra Leone, Sri Lanka, and, most recently, the Darfur region of Sudan. In these and other situations, UNHCR was not only able to extend its activities beyond the traditional tasks of refugee protection and solutions, but was also expected to do so by the international community. 
Finally, UNHCR's expansion must be seen in relation to its relationship with other actors. On one hand, the past two decades have witnessed the transformation of a refugee protection regime, supervised by UNHCR, to a more diffuse "humanitarian marketplace," in which a range of intergovernmental, international, and non-governmental agencies simultaneously co-operate and compete with each other, all of them seeking to enhance their visibility, their fundraising potential, and hence their operational presence and impact. UNHCR has not been immune to this trend, and the organization's continued expansion is in some senses a testament to its effective participation in this marketplace.

On the other hand, many of the dozen or so key states that provide the bulk of UNHCR's funding have expressed persistent wariness with regard to the organization's expansion, often expressing the opinion that the organization should return to its "core mandate," which they consider to be that of providing refugees with protection in developing regions.

For reasons that warrant further research, however, donor states have not used the power of the purse to curtail UNHCR's activities. Indeed, they have funded and thereby facilitated it. Perhaps we can conclude from these developments that donor state anxiety surrounding UNHCR's expansion into areas beyond the realm of refugee protection is in practice outweighed by their recognition of the very real humanitarian needs which the organization is helping to meet.

\section{Notes}

1. Susan F. Martin et al., The Uprooted (Lanham, MD: Lexington Books, 2005).

2. The title of an article published in numerous newspapers by High Commissioner Antonio Guterres in November and December 2007.

3. Independent Commission on International Humanitarian Issues, Winning the Human Race (London: Zed Books, 1988), 112.

4. "Climate Change, Natural Disasters and Human Displacement: A UNHCR Perspective" (Geneva: UNHCR, October 2008).

5. "Revised note on the applicability of Article 1D of the 1951 Convention to Palestinian Refugees," UNHCR, October 2009, online: http://www.unhcr.org/refworld/ pdfid/4add77d42.pdf.

6. Antonio Guterres, "People on the Move" (see note 2 above).

7. Antonio Guterres, "Millions Uprooted: Saving Refugees and the Displaced," Foreign Affairs, September-October 2008, 90 .

Jeff Crisp, Ph.D., is Head of UNHCR's Policy Development and Evaluation Service and former Director of Policy and Research at the Global Commission on International Migration. This article is written in a personal capacity and does not reflect the views of UNHCR. 